\title{
Opsoclonus-Myoclonus Syndrome Post-Vaccination and Viral Illness
}

\author{
Amanda L. Piquet, Milind Kothari, David Ermak, Aiesha Ahmed \\ Department of Neurology, The Pennsylvania State University Hershey Medical Center, Hershey, USA. \\ Email: aro863@gmail.com
}

Received March $11^{\text {th }}, 2012$; revised April $14^{\text {th }}, 2012$; accepted May $16^{\text {th }}, 2012$

\begin{abstract}
Opsoclonus-myoclonus syndrome is a rare condition with dyskinesia of eye movements and myoclonic movements of the trunk and limbs. It is linked to malignancies, infections and other conditions. We present a case of post-vaccination opsoclonus-myoclonus syndrome. We believe that our patient also experienced a viral illness post-vaccination and prior to the development of opsoclonus-myoclonus. The vaccination in combination with the viral illness potentiated the immune mechanism thought to be noted in this condition. This was supported by her recovery after receiving immunotherapy.
\end{abstract}

Keywords: Opsoclonus; Myoclonus; Ataxia; Immunotherapy

\section{Introduction}

Opsoclonus is a dyskinesia of eye movements that persist during eye closure and sleep [1]. Opsoclonus is typically associated with myoclonic jerks of the trunk, limbs, and head giving rise to the name "opsoclonus-myoclonus syndrome (OMS)". OMS is a rare disorder and is associated with infections or paraneoplastic mechanisms. Tumors commonly associated with OMS are small cell lung cancer, breast cancer, ovarian cancers [2] and neuroblastoma $[3,4]$. Other less common conditions related to OMS are HIV [5], toxins, pregnancy [1], and viral encephalopathic conditions (e.g. coxsackie virus, rubella and mumps) [6]. Recently, West Nile virus [7], Lyme disease [8], and Varicella-zoster virus [9] have also been linked. In this case, the possible etiology of influenza vaccine with subsequent flu like illness causing an immune-mediated response triggering the OMS and its treatment is discussed.

\section{Case Report}

The patient is a 30-year-old woman who noted an acute onset of dizziness two weeks prior to presentation to neurology. She began to have nausea and vomiting a few days after the onset of dizziness. Subsequently, she noted unsteady gait and jerkiness of eye movements bilaterally. Of note, she had received the flu vaccination two weeks prior to the onset of her symptoms. She also reported mild, self limited flu like symptoms three days after receiving the flu shot. Her past medical history, family and social history were unremarkable. She was not on any medications. On examination, she was alert and showed normal mentation. Cranial nerve examination was intact except for opsoclonus. On motor examination, spontaneous myoclonus was noted throughout her body, which was exaggerated by active movement. She had full strength and intact reflexes symmetrically. She was unable to stand independently secondary to severe truncal ataxia. She also showed significant appendicular ataxia during finger to nose testing. Her sensory exam was intact to all modalities.

Work up included extensive blood test and spinal fluid analysis which were unremarkable and summarized in Tables 1 and 2. MRI of the brain with and without contrast was normal. CT scans of chest, pelvis, and abdomen were unremarkable. Mammogram was also unremarkable.

She was diagnosed with idiopathic OMS. In this case, the onset of her OMS was thought to be related to the influenza vaccination and possible viral infection acting as a second insult. Symptomatic treatment with clonazepam and levetiracetam was unhelpful. She was given intravenous methylprednisolone $(1 \mathrm{~g} / \mathrm{d})$ for 3 days which showed minimal improvement. Plasmapheresis was initiated. She showed improvement after 6 exchanges. Upon discharge she had persistent saccadomania but only on upgaze, continued myoclonic jerking of the head, and a kinetic tremor bilaterally in her upper extremities. She continued with weekly plasma exchanges for six weeks as an outpatient. Five months after her last plasma exchange, 
Table 1. CSF studies.

\begin{tabular}{ll}
\hline CSF & Results \\
\hline Gram Smear & No organisms, +1 WBC \\
Culture & No growth 3 days \\
Nucleated cells & 6 cells \\
Red blood cells & 2 cells \\
Glucose & 57 \\
Protein & 52 \\
VDRL & Non-reactive \\
Lactate & 1.2 \\
LDH & 238 \\
EBV by PCR & Negative \\
CMV IgM & Negative \\
West Nile Virus: IgM, PCR, culture & Negative \\
Lyme Disease PCR & Negative \\
Crytococcal Antigen & Negative \\
VZV by PCR & Negative \\
Paraneoplastic Autoantibodies Panel & \\
ANNA-1/anti-Hu & Negative at $<1: 2$ \\
ANNA-2/anti-Ri & Negative at $<1: 2$ \\
ANNA-3 & Negative at $<1: 2$ \\
AGNA-1 & Negative at $<1: 2$ \\
PCA-1/anti-Yo & Negative at $<1: 2$ \\
PCA-2 & Negative at $<1: 2$ \\
PCA-Tr & Negative at $<1: 2$ \\
Amphiphysin Ab & Negative at $<1: 2$ \\
CRMP-5-IgG/anti-CV2 & Negative at $<1: 2$ \\
\hline & \\
\hline
\end{tabular}

Table 2. CSF studies.

\begin{tabular}{ll}
\hline Serum & Results \\
\hline HIV & Negative \\
T. Whipelii & Negative \\
Endomysial IgA antibody & $<3$ (Negative) \\
Lyme IgM/IgG antibodies & Negative \\
ANA & \\
$\quad$ Anti-SS-A & Negative \\
$\quad$ Anti-SS-B & Negative \\
$\quad$ Anti-Smith & Negative \\
$\quad$ Anti-Jo-1 & Negative \\
Scl-70 & Negative \\
Centromere B & Negative \\
dsDNA & Negative \\
Histone & Negative \\
Paraneoplastic Antibodies & \\
Anti-Hu & Negative \\
Anti-Yo & Negative \\
Anti-Ri & Negative \\
Serum protein electrophoresis & Normal \\
Immunofixation of serum & Normal polyclonal distribution \\
\hline & of immunoglobulins \\
\hline
\end{tabular}

the patient's neurological exam showed minimal abnormality.

\section{Discussion}

The immunopathogenesis of OMS is poorly understood. There appears to be humoral and cell-mediated immune mechanisms involved both in paraneoplastic and idiopathic syndromes [1]. In many cases the symptoms are reversible after treatment with immunotherapy [1,2,10]. In idiopathic OMS cases, most patients are seronegative for antineuronal antibodies, as in this case. Our patient received the influenza vaccine two weeks prior the onset of neurological symptoms. Given that humoral immune mechanisms seem to play a role in OMS, it could be possible that the vaccine or a combination of vaccine and mild viral infection generated an immune response that lead to antibodies causing neuronal dysfunction. There are other case reports of post-vaccine as well as post viral OMS. One case describes OMS after receiving the HPV vaccination [11] and another following Rubella vaccination [12]. Bhatia et al described a patient with only myoclonus two weeks after symptoms of influenza [13]. Our patient also developed symptoms around two weeks of receiving flu vaccination. However, our patient also developed a mild flu like illness around the time of vaccination the fact that this patient improved with plasmapheresis provides additional support for an immune related response causing OMS.

\section{Conclusion}

In general the clinical course of idiopathic OMS syndrome in adults has a good recovery accelerated by the use of immunotherapy [1,2,10]. Immunotherapy should be initiated along with a complete work up for underlying malignancy, infectious, systemic diseases and toxic etiology. The vaccination in combination with the viral illness potentiated the immune mechanism thought to be noted in this condition. This was supported by her recovery after receiving immunotherapy.

\section{REFERENCES}

[1] A. Wong, “An Update on Opsoclonus,” Current Opinion in Neurology, Vol. 20, No. 1, 2007, pp. 25-31. doi:10.1097/WCO.0b013e3280126b51

[2] S. J. Groiss, M. Siebler and A. Schnitzler, "Full Recovery of Adult Onset Opsoclonus Myoclonus Syndrome after Early Immunotherapy: A Case Report," Movement Disorders, Vol. 26, No. 10, 2011, pp. 1805-1807. doi:10.1002/mds.23854

[3] A. Kirsten, S. Beck, V. Fuhlhuber, M. Kaps, T. Kreutz, M. Korfei, S. Schmitt, K. T. Preissner and F. Blaes, "New Autoantibodies in Pediatric Opsoclonus Myoclonus Syndrome," Annals of the New York Academy of Sciences, 
Vol. 1110, 2007, pp. 256-260. doi:10.1196/annals.1423.027

[4] L. Raffaghello, M. Conte, E. De Grandis and V. Pistoia, "Immunological Mechanisms in Opsoclonus-Myoclonus Associated Neuroblastoma," European Journal of Paediatric Neurology, Vol. 13, No. 3, 2009, pp. 219-223. doi:10.1016/j.ejpn.2008.04.012

[5] N. Kanjanasut, K. Phanthumchinda and R. Bhidayasiri, "HIV-Related Opsoclonus-Myoclonus-Ataxia Syndrome: Report on Two Cases," Clinical Neurology and Neurosurgery, Vol. 112, No. 7, 2010, pp. 572-574. doi:10.1016/j.clineuro.2010.03.024

[6] K. B. Digre, "Opsoclonus in Adults. Report of Three Cases and Review of the Literature," Archives of Neurology, Vol. 43, No. 11, 1986, pp. 1165-1175. doi:10.1001/archneur.1986.00520110055016

[7] A. Alshekhlee, B. Sultan and K. Chandar, "Opsoclonus Persisting during Sleep in West Nile Encephalitis,” Archives of Neurology, Vol. 63, No. 9, 2006, pp. 1324-1326. doi:10.1001/archneur.63.9.1324

[8] L. Peter, J. Jung, C. Tilikete, P. Ryvlin and F. Mauguiere, "Opsoclonus-Myoclonus as a Manifestation of Lyme Disease,” Journal of Neurology, Neurosurgery \& Psychiatry, Vol. 77, No. 9, 2006, pp. 1090-1091. doi:10.1136/jnnp.2006.091728

[9] V. Medrano, C. Royo-Villanova, J. J. Flores-Ruiz, A. P. Sempere and S. Mola-Caballero de Roda, "Parainfectious Opsoclonus-Myoclonus Syndrome Secondary to VaricellaZoster Virus Infection,” Revista de Neurologia, Vol. 41, No. 8, 2005, pp. 507-508.

[10] L. Bataller, F. Graus, A. Saiz and J. J. Vilchez, “Clinical Outcome in Adult Onset Idiopathic or Paraneoplastic Opsoclonus-Myoclonus,” Brain, Vol. 124, No. 2, 2001, pp. 437-443. doi:10.1093/brain/124.2.437

[11] J. E. McCarthy and J. Filiano, “Opsoclonus Myoclonus after Human Papilloma Virus Vaccine in a Pediatric Patient,” Parkinsonism \& Related Disorders, Vol. 15, No. 10, 2009, pp. 792-794. doi:10.1016/j.parkreldis.2009.04.002

[12] F. Lapenna, L. Lochi, M. de Mari, G. Iliceto and P. Lamberti, "Post-Vaccinic Opsoclonus-Myoclonus Syndrome: A Case Report," Parkinsonism \& Related Disorders, Vol. 6, No. 4, 2000, pp. 241-242. doi:10.1016/S1353-8020(00)00020-1

[13] K. Bhatia, P. D. Thompson and C. D. Marsden, "'Isolated' Postinfectious Myoclonus," Journal of Neurology, Neurosurgery \& Psychiatry, Vol. 55, No. 11, 1992, pp. 1089-1091. doi:10.1136/jnnp.55.11.1089 